Accepted refereed manuscript of: Lades L, Egan M, Delaney L \& Daly M (2017) Childhood self-control and adult pension participation, Economics Letters, 161, pp. 102-104. DOI: 10.1016/j.econlet.2017.09.025

(C) 2017, Elsevier. Licensed under the Creative Commons Attribution-NonCommercial-NoDerivatives 4.0 International http://creativecommons.org/licenses/by-nc-nd/4.0/

\title{
Childhood self-control and adult pension participation
}

\author{
Leonhard K. Lades ${ }^{\mathrm{a}^{*}}$, Mark Egan ${ }^{\mathrm{b}}$, Liam Delaney ${ }^{\mathrm{c}}$, Michael Daly ${ }^{\mathrm{a}, \mathrm{c}}$
}

${ }^{a}$ Behavioural Science Centre, University of Stirling, UK.

${ }^{\mathrm{b}}$ Behavioural Insights Team, London, UK.

${ }^{\mathrm{c} U C D}$ Geary Institute, University College Dublin, Ireland.

*Corresponding author (1.k.lades@stir.ac.uk)

\begin{abstract}
Self-control problems have been proposed as a key reason for low pension saving rates, yet evidence of this link remains scarce. We test the association between childhood self-control and adult pension participation using data from 14,223 individuals from two nationally-representative British cohorts. We find that a 1 standard deviation increase in self-control predicts a 4-5 percentage point higher probability of having a pension. Mediation analysis shows that about 50-60 percent of this association is explained by the contribution of self-control to a range of factors (e.g. education, economic status, home-ownership) which are associated with pension uptake throughout adulthood.
\end{abstract}

Keywords: self-control, pension, retirement, cohort studies

JEL Codes: D14; D91; J26 


\section{Introduction}

Saving for retirement is one of the most important decisions in life. However, many people fail to save for retirement despite making plans to do so (Choi et al. 2002), and saving rates in industrialized countries remain low. Research suggests that self-control failures, conceptualized as dynamically inconsistent preferences, are an important cause of the discrepancy between plans to save and actual saving (Beshears et al. 2015). This has inspired businesses and governments to set up automatic pension enrolment policies in the UK and the US (Thaler and Benartzi 2004). However, empirical evidence on the link between self-control and saving for retirement is scarce and restricted mainly to small sample cross-sectional studies (Jacobs-Lawson and Hershey 2005) and to studies linking self-control to financial behavior more generally (e.g. (Moffitt et al. 2011).

In this note, we draw on a total sample of 14,223 individuals from the British Cohort Study (BCS) and the British National Child Development Study (NCDS) to examine the relationship between childhood self-control (measured at ages 10 and 7/11, respectively ) and adult pension participation (at ages 42 and 50, respectively). Additionally, we investigate whether differences in economic success in adulthood may act as a channel through which early self-control links to pension participation later in life.

\section{Data}

The BCS and the NCDS are nationally representative, longitudinal birth cohort studies. Both cohorts contain a sample of over 17,000 children born in a single week in 1970 and 1958, respectively. Both studies also contain a rich set of childhood socio-demographic variables and records of later economic activity. Childhood self-control is measured in the BCS at age 10 using the average of 9 teacher-rated items related to attentional control and perseverance, measured on a visual analogue scale ranging from "not at all" to "a great deal" and scaled from 1 to 47 . In the NCDS, self-control is measured at ages 7 and 11 from 13 teacher-rated binary items measuring attentional control, persistence, and impulsive behavior. We take the average of both waves or utilize a single wave if only one is available. Evidence for the reliability of both scales and their convergence with contemporary self-control measures is provided in Daly et al. (2015). We measure pension participation at age 42 in the BCS and age 50 in the NCDS, at which ages participants were asked "Can you tell me which, if any, of the pensions on this card you have. This 
includes all pensions you are currently contributing to or pensions you have contributed to in the past?"

In the baseline regressions, we control for childhood intelligence, gender, and socioeconomic status at birth. In additional regressions, we add adult measures for educational attainment, economic status, marital status, home ownership, number of children, and lifetime unemployment. We selected these mediating variables as they have been shown to be predicted by self-control (Moffitt et al. 2011) and to be predictive of retirement savings behavior (e.g. Ekerdt 2010). After dropping observations due to missing data, our sample sizes are 5,834 and 8,389 in the BSC and NCDS, respectively. Table 1 presents the descriptive statistics.

Table 1.

Descriptive statistics

\begin{tabular}{|c|c|c|}
\hline & $\operatorname{BCS}(n=5,834)$ & $\operatorname{NCDS}(n=8,389)$ \\
\hline Outcome measure & Age 42 & Age 50 \\
\hline Any pension & $78.4 \%$ & $78.5 \%$ \\
\hline Childhood covariates & Age 10 & Age 7, 11 \\
\hline Self-control $^{\mathrm{a}}$ & $32.1(9.9)$ & $11.7(1.6)$ \\
\hline Intelligence $^{\mathrm{b}}$ & $78.2(13.7)$ & $45.3(15.5)$ \\
\hline Female & $53.0 \%$ & $50.9 \%$ \\
\hline Socioeconomic status & At birth & At birth \\
\hline I (highest) & $5.5 \%$ & $4.2 \%$ \\
\hline II & $12.7 \%$ & $13.0 \%$ \\
\hline III & $58.0 \%$ & $56.0 \%$ \\
\hline IV & $13.1 \%$ & $10.9 \%$ \\
\hline $\mathrm{V}$ (lowest) & $4.7 \%$ & $7.5 \%$ \\
\hline Other & $5.7 \%$ & $4.3 \%$ \\
\hline Missing & $0.3 \%$ & $4.1 \%$ \\
\hline Adult covariates & Age 42 & Age 50 \\
\hline \multicolumn{3}{|c|}{ National Vocational Qualification (NVQ) } \\
\hline None & $7,9 \%$ & $10.6 \%$ \\
\hline Level 1 (lowest) & $7,2 \%$ & $11.1 \%$ \\
\hline Level 2 & $26,0 \%$ & $25.4 \%$ \\
\hline Level 3 & $15,7 \%$ & $17.5 \%$ \\
\hline Level 4 & $35,5 \%$ & $31.2 \%$ \\
\hline Level 5 (highest) & $7,8 \%$ & $4.2 \%$ \\
\hline \multicolumn{3}{|l|}{ Marital status } \\
\hline Separated \& widowed & $1.7 \%$ & $4.6 \%$ \\
\hline Married \& civil partnership & $64.1 \%$ & $69.4 \%$ \\
\hline Divorced & $11.0 \%$ & $15.7 \%$ \\
\hline Single & $23.3 \%$ & $10.3 \%$ \\
\hline \multicolumn{3}{|l|}{ Economic status } \\
\hline Full time employed & $54.54 \%$ & $56.4 \%$ \\
\hline
\end{tabular}


Part time employed

Full time self-employed

Part time self-employed

Unemployed

Sick

Home

Other

Housing situation

Own - outright

Own - buying with mortgage

Rent \& mortgage

Rent

Live rent free

Other

Kids

Lifetime unemployment

0

1-12 months
$18.22 \%$

$10.95 \%$

$3.21 \%$

$1.89 \%$

$2.74 \%$

$7.34 \%$

$1.11 \%$

$10.1 \%$

$66.7 \%$

$0.7 \%$

$19.1 \%$

$2.4 \%$

$1.1 \%$

1.7

Age 16-48

$76.6 \%$

$14.4 \%$

$9.0 \%$
$15.1 \%$

$11.1 \%$

$2.4 \%$

$2.5 \%$

$5.2 \%$

$5.2 \%$

$2.2 \%$

$24.1 \%$

$59.8 \%$

$0.4 \%$

$13.7 \%$

$1.3 \%$

$0.6 \%$

1.8

Age 16-50

$62.6 \%$

$23.7 \%$

$13.7 \%$

${ }^{\mathrm{a}}$ From 1 to 47 in the BCS and from 1 to 13 in the NCDS.

${ }^{\mathrm{b}}$ From 0 to 141 in the BCS and from 0 to 80 in the NCDS.

\section{Results}

To test whether childhood self-control predicts later life pension participation we specify probit models regressing the binary variable "any pension" on childhood self-control and the 3 childhood covariates as indicated in columns 1 and 3 in table 2 . In columns 2 and 4, we add adult covariates to the regression. We focus on having any pension as the outcome variable since employer pensions and private pensions are strong substitutes. 
Table 2:

Childhood self-control predicting pension participation. Marginal effects from probit regressions.

\begin{tabular}{|c|c|c|c|c|}
\hline & \multicolumn{2}{|c|}{$\operatorname{BCS}(n=5,834)$} & \multicolumn{2}{|c|}{$\operatorname{NCDS}(\mathrm{n}=8,389)$} \\
\hline Model & (1) & (2) & (3) & (4) \\
\hline Self-control & $\begin{array}{l}0.049 * * * \\
(0.006)\end{array}$ & $\begin{array}{c}0.024 * * * \\
(0.005)\end{array}$ & $\begin{array}{c}0.043 * * * \\
(0.005)\end{array}$ & $\begin{array}{c}0.016^{* * * *} \\
(0.004)\end{array}$ \\
\hline Intelligence & $\begin{array}{c}0.054 * * * \\
(0.006)\end{array}$ & $\begin{array}{c}0.024 * * * \\
(0.006)\end{array}$ & $\begin{array}{c}0.065^{* * * *} \\
(0.005)\end{array}$ & $\begin{array}{l}0.015 * * \\
(0.005)\end{array}$ \\
\hline Female & $\begin{array}{c}-0.087 * * * \\
(0.011)\end{array}$ & $\begin{array}{c}-0.066 * * * \\
(0.012)\end{array}$ & $\begin{array}{c}-0.171 * * * \\
(0.009)\end{array}$ & $\begin{array}{c}-0.115^{* * *} * \\
(0.009)\end{array}$ \\
\hline $\begin{array}{c}\text { Socioeconomic } \\
\text { I (highest) }\end{array}$ & $\begin{array}{l}\text { atus at birtl } \\
\text { (base) }\end{array}$ & (base) & (base) & (base) \\
\hline II & $\begin{array}{c}- \\
-0.057 * \\
(0.026)\end{array}$ & $\begin{array}{c}- \\
-0.045 \\
(0.026)\end{array}$ & $\begin{array}{c}0.004 \\
(0.024)\end{array}$ & $\begin{array}{c}0.011 \\
(0.022)\end{array}$ \\
\hline III & $\begin{array}{l}-0.056^{*} \\
(0.022)\end{array}$ & $\begin{array}{l}-0.039 \\
(0.023)\end{array}$ & $\begin{array}{l}-0.037 \\
(0.022)\end{array}$ & $\begin{array}{l}-0.017 \\
(0.021)\end{array}$ \\
\hline IV & $\begin{array}{c}-0.132 * * * \\
(0.026)\end{array}$ & $\begin{array}{c}-0.101 * * * \\
(0.026)\end{array}$ & $\begin{array}{c}-0.081 * * \\
(0.025)\end{array}$ & $\begin{array}{l}-0.042 \\
(0.023)\end{array}$ \\
\hline V (lor & $\begin{array}{c}-0.150 * * * \\
(0.034)\end{array}$ & $\begin{array}{l}-0.076^{*} \\
(0.031)\end{array}$ & $\begin{array}{c}-0.104 * * * \\
(0.027)\end{array}$ & $\begin{array}{l}-0.046 \\
(0.025)\end{array}$ \\
\hline Other & $\begin{array}{c}-0.156 * * * \\
(0.032)\end{array}$ & $\begin{array}{c}-0.095 * * \\
(0.030)\end{array}$ & $\begin{array}{c}-0.077 * * \\
(0.030)\end{array}$ & $\begin{array}{l}-0.034 \\
(0.027)\end{array}$ \\
\hline Missing & $\begin{array}{l}-0.160 \\
(0.098)\end{array}$ & $\begin{array}{l}-0.121 \\
(0.088)\end{array}$ & $\begin{array}{l}-0.063 * \\
(0.030)\end{array}$ & $\begin{array}{c}-0.032 \\
(0.028)\end{array}$ \\
\hline Adult covariates & No & Yes & No & Yes \\
\hline
\end{tabular}

Self-control and intelligence are standardized. Standard errors in parentheses.

$* * \mathrm{p}<0.01, * \mathrm{p}<0.05$.

Adult covariates are education, economic status, marital status, home ownership, and number of children, and lifetime unemployment.

Our main result is that more self-controlled children are more likely to have a pension as adults. When controlling for childhood covariates only, a one standard deviation increase in childhood self-control predicts a 4-5 percentage point higher probability of having a pension (compared to an average pension participation of $78.4 \%$ in the BCS and of $78.5 \%$ in the NCDS). The predictive strength of childhood self-control is comparable to childhood intelligence or the effect of moving from the highest SES to middle SES at birth. When adding the adult covariates, the association between childhood self-control and later life pension participation decreases, but remains significant. ${ }^{1}$

1 There are direct effects of the adult covariates: In particular, education and full-time employment predict pension participation. 
To identify the pathways that explain why childhood self-control predicts adult pension participation, we conduct a mediation analysis using the $k h b$ procedure described in Kohler, Karlson, and Holm (2011). This method is appropriate for binary outcomes such as pension participation and adjusts for rescaling issues that occur when making naïve cross-model comparisons of non-linear models, e.g. with categorical mediators. Table 3 shows that 47\% (BCS) and $60 \%$ (NCDS) of the association between childhood self-control and pension participation is explained by the adult mediators. Education, economic status, and home ownership explain most ( $82 \%$ and $74 \%$, respectively) of the indirect effect of self-control on having a pension, suggesting that much of the pathway between childhood self-control and adult pension participation is via these economic factors.

Table 3:

Decomposition of total effect of childhood self-control on pension participation via 6 adult covariates.

\begin{tabular}{|c|c|c|c|c|}
\hline & \multicolumn{2}{|c|}{ BCS $(n=5,834)$} & \multicolumn{2}{|c|}{ NCDS $(n=8,389)$} \\
\hline \multirow[t]{2}{*}{ Model } & \multicolumn{2}{|l|}{ (1) } & \multicolumn{2}{|l|}{ (2) } \\
\hline & Coefficient & $\mathrm{Z}$ & Coefficient & $\mathrm{Z}$ \\
\hline \multicolumn{5}{|c|}{ Coefficients for childhood self-control } \\
\hline Total effect & 0.046 & 8.61 & 0.041 & 9.38 \\
\hline Direct effect & 0.024 & 4.45 & 0.016 & 3.64 \\
\hline Indirect effect & 0.022 & - & 0.025 & - \\
\hline via Education & 0.007 & - & 0.006 & - \\
\hline Economic status & 0.006 & - & 0.006 & - \\
\hline Marital status & 0.001 & - & 0.002 & - \\
\hline Unemployment & 0.002 & - & 0.004 & - \\
\hline Kids & 0.001 & - & 0.001 & - \\
\hline Home-ownership & 0.005 & - & 0.006 & - \\
\hline \multicolumn{5}{|l|}{ Relative measures } \\
\hline Mediation percentage & $47.4 \%$ & & $60.4 \%$ & \\
\hline via Education & $33.9 \%$ & - & $25.5 \%$ & - \\
\hline Economic status & $26.2 \%$ & - & $24.5 \%$ & - \\
\hline Marital status & $5.2 \%$ & - & $6.1 \%$ & - \\
\hline Unemployment & $9.0 \%$ & - & $16.0 \%$ & - \\
\hline Kids & $3.5 \%$ & - & $3.9 \%$ & - \\
\hline Home-ownership & $22.2 \%$ & - & $24.0 \%$ & - \\
\hline
\end{tabular}

The total effect excludes adult covariates, the direct effect includes adult covariates, and the indirect effect is the cumulative effect of the adult covariates. Total effects differ slightly from those in Table 2 because the estimator implemented in Kohler et al (2011) expresses the total effect on the same scale as the direct effect. The total effect in table 2 expresses the effect on a different scale and is therefore not comparable to the direct effect. 


\section{Discussion}

This note contributes empirical evidence on the link between self-control and financial decision making showing a positive link between childhood self-control and pension participation in a longitudinal study that avoids issues of reversed causality. Pension funds are an illiquid form of saving and could be used as a commitment device by individuals who are aware of their self-control problems (Laibson 2015). This would imply that people low in self-control would have a high demand for pensions. But we find the opposite which suggests that the role of self-control in predicting pension participation is via inertia and procrastination among those with low self-control rather than via a demand for commitment.

The note also contributes to recent research showing that already in childhood, individuals differ in their non-cognitive traits and that these differences predict economically relevant lifetime outcomes (Daly, et al., 2015; Moffitt et al., 2011). The study by Moffitt et al. (2011) is closest to the present note as it shows in a sample from New Zealand that childhood self-control predicts higher scores on a composite index of "financial building blocks" (i.e. the sum of having a retirement plan, home ownership, stocks, or business investments) providing initial evidence linking self-control and pension savings.

Whilst the capacity for self-control is under substantial genetic influence (e.g. Beaver et al. 2009), self-control also appears to be adversely affected by childhood stress and disadvantage and has been pinpointed as a malleable trait that can be fostered through early intervention programs (Blair 2010; Moffitt et al. 2011; Piquero et al. 2016). As such policy-strategies aiming to ameliorate psychosocial adversity or enhance self-control through early education and care interventions could produce long-term societal gains - which our findings suggest may include increased pension savings across life.

The note has limitations. As childhood self-control is not randomly assigned, the data is observational and we cannot make causal inferences despite the longitudinal structure. For the direct effect between self-control and pension participation to have a causal interpretation in the mediation analysis, we need to assume that two identifiability assumptions are satisfied: There must not be unmeasured confounding of the link between self-control and pension participation and the link between the adult mediators and pension participation (Valeri and Van der Weele 
2013). We do control for several potentially confounding factors, but cannot rule out the possibility that unobserved variables may explain the above links. Further, attrition from childhood may have affected the results and modern self-control measures were unavailable due to the long-term nature of the study. Finally, our measure of pension participation is self-reported and we lack objective data about whether and how much cohort members save.

\section{Conclusion}

This note shows in two longitudinal datasets $(n=14,223)$ that childhood self-control predicts pension participation up to four decades later. When controlling for intelligence and social background, a one standard deviation increase in childhood self-control predicts a 4-5 percentage point higher probability of having a pension (compared to an average of about $78 \%$ ). This relationship can be largely explained by lifetime outcomes such as educational attainment, economic activity, and home ownership.

\section{Acknowledgements}

We are grateful to The Centre for Longitudinal Studies, Institute of Education, for their management of these data and to the UK Data Archive for making them available. However, these organizations bear no responsibility for the analysis or interpretation of the data.

\section{References}

Beaver, Kevin M., J. Eagle Schutt, Brian B. Boutwell, Marie Ratchford, Kathleen Roberts, and J. C. Barnes. 2009. "Genetic and Environmental Influences on Levels of Self-Control and Delinquent Peer Affiliation: Results from a Longitudinal Sample of Adolescent Twins." Criminal Justice and Behavior 36 (1): 41-60.

Beshears, John, James J. Choi, Christopher Harris, David Laibson, Brigitte C. Madrian, and Jung Sakong. 2015. "Self Control and Commitment: Can Decreasing the Liquidity of a Savings Account Increase Deposits?” National Bureau of Economic Research.

Blair, Clancy. 2010. "Stress and the Development of Self-Regulation in Context." Child Development Perspectives 4 (3): 181-188.

Choi, James J., David Laibson, Brigitte C. Madrian, and Andrew Metrick. 2002. "Defined Contribution Pensions: Plan Rules, Participant Choices, and the Path of Least Resistance." Tax Policy and the Economy 16 (January): 67-113.

Daly, Michael, Liam Delaney, Mark Egan, and Roy F. Baumeister. 2015. "Childhood SelfControl and Unemployment Throughout the Life Span Evidence From Two British Cohort Studies." Psychological Science 26 (6): 709-723.

Ekerdt, David J. 2010. "Frontiers of Research on Work and Retirement." The Journals of Gerontology: Series B 65B (1): 69-80. 
Jacobs-Lawson, Joy M., and Douglas A. Hershey. 2005. "Influence of Future Time Perspective, Financial Knowledge, and Financial Risk Tolerance on Retirement Saving Behaviors."

Financial Services Review; Atlanta 14 (4): 331-44.

Kohler, Ulrich, Kristian Bernt Karlson, and Anders Holm. 2011. "Comparing Coefficients of Nested Nonlinear Probability Models." Stata Journal 11 (3): 420-38.

Laibson, David. 2015. "Why Don't Present-Biased Agents Make Commitments?" American Economic Review 105 (5): 267-72.

Moffitt, Terrie E, Louise Arseneault, Daniel Belsky, Nigel Dickson, Robert J Hancox, HonaLee Harrington, Renate Houts, et al. 2011. "A Gradient of Childhood Self-Control Predicts Health, Wealth, and Public Safety." Proceedings of the National Academy of Sciences 108 (7): 2693-2698.

Piquero, Alex R., Wesley G. Jennings, David P. Farrington, Brie Diamond, and Jennifer M. Reingle Gonzalez. 2016. "A Meta-Analysis Update on the Effectiveness of Early SelfControl Improvement Programs to Improve Self-Control and Reduce Delinquency." Journal of Experimental Criminology 12 (2): 249-264.

Thaler, R. H., and S. Benartzi. 2004. "Save More Tomorrow(TM): Using Behavioral Economics to Increase Employee Saving." Journal of Political Economy 112 (1): 164-187.

Valeri, Linda, and Tyler J. VanderWeele. 2013. "Mediation Analysis Allowing for Exposuremediator Interactions and Causal Interpretation: Theoretical Assumptions and Implementation with SAS and SPSS Macros.” Psychological Methods 18 (2): 137. 